\title{
Diel vertical migration related to foraging success in snapper Chrysophrys auratus larvae
}

\author{
Hannah M. Murphy ${ }^{1,2, *}$, Gregory P. Jenkins ${ }^{1,3}$, Paul A. Hamer ${ }^{3}$, Stephen E. Swearer ${ }^{1}$ \\ ${ }^{1}$ Department of Zoology, University of Melbourne, Parkville, Victoria 3010, Australia \\ ${ }^{2}$ Victorian Marine Science Consortium, PO Box 114, Queenscliff, Victoria 3225, Australia \\ ${ }^{3}$ Fisheries Research Branch, Department of Primary Industries Victoria, PO Box 114, Queenscliff, Victoria 3225, Australia
}

\begin{abstract}
The vertical distributions of marine fish larvae can change markedly over time due to changes in diel vertical migration (DVM). DVM is thought to be influenced by a number of factors including light levels and prey availability. In Port Phillip Bay, Australia, the DVM of snapper Chrysophrys auratus (Sparidae) larvae and their prey were investigated using depth-stratified sampling (four depths: surface, 4, 8, $11 \mathrm{~m}$ ) over 4 sampling periods of $24 \mathrm{~h}$. We sampled ichthyoplankton at the same location twice in 2 spawning seasons (austral summers of 2008/09 and 2009/10). Sufficient snapper larvae for analysis of DVM behaviour occurred once in each season. At both $24 \mathrm{~h}$ sampling times, snapper larvae displayed the same DVM behaviour of nocturnal diffusion and diurnal aggregation at $\sim 4 \mathrm{~m}$ depth. The water column was homogenous for temperature, salinity, dissolved oxygen and fluorescence during the two $24 \mathrm{~h}$ periods. Two out of 6 important zooplankton prey of snapper larvae were also aggregated at $\sim 4 \mathrm{~m}$ depth during the day. Gut analyses indicated that larvae only fed during daylight hours and had an average digestion time of 3 to $5 \mathrm{~h}$. Snapper larvae had highest foraging success at $4 \mathrm{~m}$ depth, which was supported by minimal digestion of prey at time of capture. This suggests that the observed DVM was related to feeding success, and that $4 \mathrm{~m}$ depth provided optimal foraging conditions. These results have important implications for developing individual-based biophysical models of larval transport that include interaction with prey fields and larval foraging success.
\end{abstract}

KEY WORDS: Light levels · Marine fish larvae $\cdot$ Food availability Resale or republication not permitted without written consent of the publisher

\section{INTRODUCTION}

Diel vertical migration (DVM) in marine fish larvae can be a behavioural trait exhibited from the time of hatching (Leis 2004). This relatively simple, but variable, behaviour can influence the horizontal dispersal of larvae when current shear is not uniform with depth (Sponaugle et al. 2002, Leis 2006, 2007), a feature typical of both tidal and wind-driven currents. For example, as wind currents decrease exponentially with water depth (Black et al. 1993), larvae closer to the surface will often encounter stronger currents and greater horizontal displacement than larvae in the mid- or bottom sections of the water column. Tidal currents vary on a diurnal or semi-diurnal cycle, and fish larvae can migrate vertically to use ebb or flood tides to aid in retention or dispersal (Neilson \& Perry 1990).
The effect of vertical migrations on dispersal has been documented in estuarine fishes (e.g. Fortier \& Leggett 1983). The incorporation of larval behaviour, particularly vertical migration, into individual-based biophysical models (IBMs) of larval dispersal and recruitment in fish is becoming more common and is recognised as an important consideration if such models are to accurately predict individual dispersal histories (Fox et al. 2006, Leis 2007, Vikebo et al. 2007).

There are 3 main forms of DVM in marine larval fishes: nocturnal ascent (type I), where the larvae move up at dusk and down at dawn (Neilson \& Perry 1990); nocturnal descent (type II), where the larvae move down at dusk and up at dawn (Neilson \& Perry 1990); and nocturnal diffusion, where the larvae are distributed evenly throughout the water column during the night and aggregate to a specific depth during 
the day (e.g. Brewer \& Kleppel 1986, Davis et al. 1990, Jenkins et al. 1998). Diel vertical migratory behaviour can vary taxonomically, with nocturnal ascent being the most commonly observed pattern for marine fish larvae (Neilson \& Perry 1990). Vertical behaviour can also vary ontogenetically, with older larvae commonly demonstrating a more pronounced DVM pattern compared to smaller, less developed pre-flexion stages (Neilson \& Perry 1990).

Marine fish larvae may vertically migrate in response to a variety of factors, including to avoid predators (Yamashita et al. 1985), to optimise feeding success (Fortier \& Leggett 1983, Munk et al. 1989), and to influence larval dispersal (reviewed by Leis 2006). In marine temperate fish larvae, patterns of DVM behaviour have more often been interpreted as responses to prey-predator interactions than to abiotic factors (Neilson \& Perry 1990, Sabates 2004). Although a relationship between prey density and larval DVM behaviour has been found for numerous taxa, for example herring Clupea harengus (Munk et al. 1989), sandeel Ammodytes marinus (Jensen et al. 2003) and mackerel Scomber scombrus (De LaFontaine \& Gascon 1989), other studies have found no such relationship (e.g. Brewer \& Kleppel 1986, Jenkins et al. 1998). However, the relationship between prey availability and DVM may be more complicated where it is not just the availability of prey that is important, but rather, the ability of fish larvae to obtain high foraging success in relation to multiple environmental factors (Munk et al. 1989). Since the majority of marine fish larvae are visual predators (Blaxter 1986), foraging success may be a trade-off between optimal light levels, prey availability (Fortier \& Leggett 1983, Munk et al. 1989) and/or turbulence (Dower et al. 1998). Furthermore, the patterns of DVM behaviour for the same species can change among sampling periods, years and locations (Sclafani et al. 1993). This suggests that a combination of factors, such as light levels, turbidity, temperature, predation and foraging success, may be important in determining the extent and variety of DVM behaviour.

Snapper Chrysophrys auratus (Sparidae) is an important fishery species in Australia and New Zealand and displays high recruitment variation, which strongly influences the dynamics of fishery production (Francis 1993, McGlennon et al. 2000, Fowler \& Jennings 2003, Hamer \& Jenkins 2004). Recent work in Port Phillip Bay (PPB), Australia, has demonstrated that the recruitment dynamics of juvenile snapper are closely matched to those of the larval stage (Hamer et al. 2010, 2011). Understanding what influences snapper larval survival has become an important focus for research on this species throughout its wide distribution (e.g. Fowler \& Jennings 2003, Zeldis et al. 2005).
DVM behaviour of some sparid species has been investigated, and nocturnal ascent is the most common DVM pattern found in this family (e.g. Tanaka 1985, Joyeux 2001, Ruso \& Bayle-Sempere 2006). In this study, we measured the DVM behaviour of snapper larvae in PPB over four $24 \mathrm{~h}$ periods. We compared the observed larval behaviour to the measured vertical variation in a range of environmental variables, including temperature, salinity, dissolved oxygen and fluorescence; the densities of important zooplankton prey; and the foraging success of the larvae. We aimed to describe the DVM behaviour of snapper larvae and to determine its relationship to environmental factors and foraging success.

\section{MATERIALS AND METHODS}

Sampling of snapper larvae and zooplankton. Depth-stratified sampling of snapper larvae was undertaken twice in each of the austral summers of 2008/09 and 2009/10 in PPB (Fig. 1). In both years, sampling took place at the same location, which had a bottom depth of $12 \mathrm{~m}$, in the eastern region of PPB (Fig. 1). This location and depth were chosen based on previous knowledge of snapper spawning and the occurrence of larval stages (Hamer et al. 2010, 2011; Fig. 1). Sampling was initiated when snapper larvae were found in the field by a concurrent monitoring programme occurring in the same area. In both years, the $24 \mathrm{~h}$ sampling occurred once in mid-December and once in mid-January. Ichthyoplankton samples were collected continuously over $\sim 24 \mathrm{~h}(22: 00$ to $19: 00 \mathrm{~h})$ using a $500 \mu \mathrm{m}$ mesh plankton net with a circular mouth of $80 \mathrm{~cm}$ in diameter. We divided the water column into 4 strata for ichthyoplankton and zooplankton sampling: surface (top $1 \mathrm{~m}$ of the water column), 4, 8 and $11 \mathrm{~m}$ depths. The 4 strata were sampled in a random order in blocks that were repeated 9 times in each of the four $24 \mathrm{~h}$ sampling events. For each ichthyoplankton sample, the net was deployed for $12 \mathrm{~min}$ at each specified depth stratum. A closing mechanism (choker) was used to prevent the net from sampling the water column while being deployed and retrieved. A General Oceanics flowmeter (model number 2030) was used to determine the volume of water filtered in each tow. Material from the cod end was filtered through a $500 \mu \mathrm{m}$ mesh sieve and immediately preserved in $95 \%$ ethanol.

Zooplankton samples were collected using an $80 \mu \mathrm{m}$ mesh plankton net with a circular mouth of $30 \mathrm{~cm}$ in diameter. The zooplankton net was clipped to a pulley and allowed to run down the rope attached to the ichthyoplankton net until it hit the larger net. The zooplankton net was left to fish at the specified depth stra- 


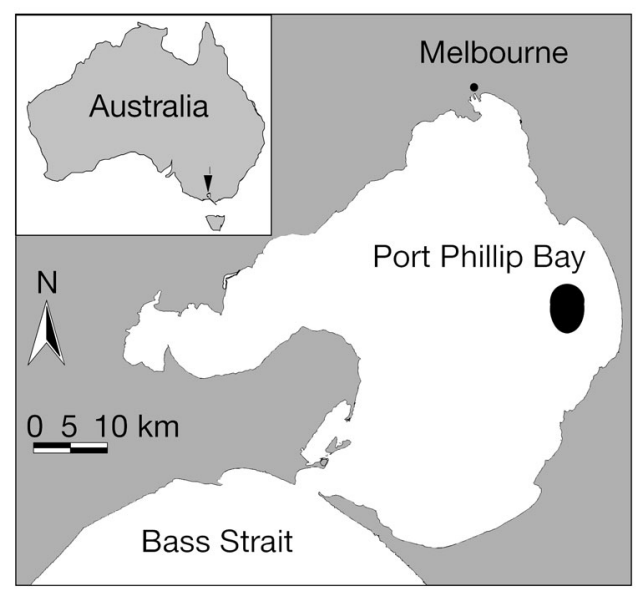

Fig. 1. Port Phillip Bay, Australia. All sampling was conducted in the same area and depth range in the eastern part of the bay (black dot)

tum for 2 min, and a closing mechanism (choker) was used to prevent the net sampling the water column while being deployed and retrieved. A General Oceanics flowmeter (model number 2030) was used to determine the volume of water filtered with each tow. Material from the cod end was filtered through a $50 \mu \mathrm{m}$ mesh sieve and immediately preserved in $4 \%$ buffered formaldehyde solution.

At the end of each block of ichthyoplankton and zooplankton tows, a Hydrolab DS4X water quality sonde was deployed to record temperature, salinity and fluorescence. We acquired data at $2 \mathrm{~m}$ intervals between the surface and the bottom of the water column. Three times throughout the $24 \mathrm{~h}$ sampling period, a Niskin bottle was used to sample water at each depth for laboratory determination of chlorophyll a (chl a) concentrations that were used to calibrate the fluorometer readings.

Foraging success. Snapper larvae were identified based on the descriptions of Neira et al. (1998). All snapper larvae were removed from ichthyoplankton samples and stored in vials with $95 \%$ ethanol until used for diet analysis.

The standard length (SL, tip of snout to tip of notochord) and gape width (distance between left and right postero-ventral tips of the articular bones; Kiorboe et al. 1985) of all intact snapper larvae were measured to $0.1 \mathrm{~mm}$ under a dissecting microscope using an ocular micrometer. No adjustments to measured SL were made to account for preservation shrinkage, although this would be expected to be minimal in $95 \%$ ethanol and similar among larvae (Theilacker 1980).

After the SL and gape width had been measured, each larva was transferred to a drop of glycerol, and the gastrointestinal tract was dissected out for dietary analysis using electrolytically sharpened tungsten needles under a dissecting microscope. Each food item in the gut contents was identified to the lowest possible taxonomic level, and its maximum width was measured. The stomach contents of all snapper larvae from each sample were analysed, except when there were more than 20 snapper larvae in a sample. When this occurred, a sub-sample of 20 snapper larvae was randomly chosen and used for stomach content analysis, and the remaining larvae were measured for SL.

Zooplankton. In the laboratory, zooplankton samples were sieved through a $40 \mu \mathrm{m}$ mesh and transferred to freshwater to give a total volume from $200 \mathrm{ml}$ to $2 \mathrm{l}$, depending on the concentration of zooplankton in the sample. Sub-samples of $1 \mathrm{ml}$ were drawn out of the suspended zooplankton sample with a HensenStempel pipette until at least 200 individuals were counted. Zooplankton was identified to the lowest taxonomic level possible.

Data analysis. Snapper larval abundances were standardised to number per $1000 \mathrm{~m}^{3}$ based on flowmeter determinations of the volume of water filtered per tow. The stomach contents of the snapper larvae were used to determine diet composition and to measure average foraging success of larvae by tow. We used $\% \mathrm{~N}$, which was the number of prey items of a category as a percentage of the total number of prey items found in the stomachs of the larvae in each tow, to compare diet composition between depths.

Zooplankton abundances per $\mathrm{m}^{3}$ were calculated using the formula:

$$
D=N \times V_{\mathrm{S}} / N_{\mathrm{A}} \times V
$$

where $N$ is the number of organisms; $N_{\mathrm{A}}$ is the number of $1 \mathrm{ml}$ aliquots; $V_{\mathrm{S}}$ is the volume of subsample; and $V$ is the volume of water filtered through the zooplankton net measured by the flowmeter.

The vertical distribution pattern of snapper larval densities was analysed using a 3-factor ANOVA in respect to date (2008/09 and 2009/10), depth strata (surface, 4, 8, and $11 \mathrm{~m}$ ) and day vs. night sampling. We used univariate tests (ANOVAs) to determine the vertical behaviour of individual taxa/groups of zooplankton. Mean larval foraging success (measured as mean number of prey per larval stomach by tow) was analysed using a 3-factor ANOVA (date, depth strata and day vs. night sampling). We used Pearson correlations to determine whether larval densities and zooplankton densities were related across plankton tows. The vertical pattern of environmental variables was analysed using ANOVAs. All data from 1 tow were eliminated from the data set (surface tow 29 from 2009/10), as it was continually an outlier when the data were transformed. We found very low numbers of both zooplankton and ichthyoplankton in this tow, which 
suggests that the nets failed to deploy properly. Snapper larval densities from both years were $\log _{10}(x+1)$ transformed, zooplankton densities were fourth-root transformed, and average larval foraging success per tow was square-root transformed to meet ANOVA requirements of homoscedasticity of variances (Levene's test: $p>0.05$ ) and normal distribution (ShapiroWilk test: $p>0.05$ ).

\section{RESULTS}

\section{Vertical behaviour of snapper larvae}

Sufficient larvae for DVM analyses were sampled in one of the two $24 \mathrm{~h}$ sampling events in each year. These 2 dates were January 2009 (hereafter 2008/09) and December 2009 (hereafter 2009/10). In total, 36 ichthyoplankton samples were taken in each of the $24 \mathrm{~h}$ periods, with 24 day tows and 12 night tows.

In 2008/09, we sampled 1283 snapper larvae ranging in size from 2.0 to $7.5 \mathrm{~mm}$ SL (mean \pm SD: $4.5 \pm$ $0.87 \mathrm{~mm}$ ), and in 2009/10, we sampled 187 snapper larvae, ranging in size from 2.5 to $6.0 \mathrm{~mm}$ SL (mean: $3.9 \pm$ $0.62 \mathrm{~mm}$ ). Using a 3-factor ANOVA (year, day vs. night sampling and depth strata), there was no significant difference in standard length between depth strata (ANOVA: $\mathrm{p}=0.761$ ) and day vs. night sampling (ANOVA: $p=0.148$ ), but there was a significant difference in mean SL between years, as the larvae from 2008/09 were $10 \%$ longer than in 2009/10 (Kolmogorov-Smirnov: $D=0.484 ; \mathrm{p}<0.001$ ).

There were significant interactions between date and day vs. night sampling and day vs. night sampling and depth strata for snapper larval densities (Table 1). Higher densities of snapper larvae were sampled in $2008 / 09$ compared to $2009 / 10$, and $21 \%$ more larvae were sampled at night compared to day in 2008/09 (Fig. 2a,b). For both years, snapper larvae showed

Table 1. Chrysophrys auratus. Analysis of variance of log $(x+1)$ transformed snapper larval densities with respect to date, day vs. night sampling and depth strata over 2 sampling periods

\begin{tabular}{|lrrrr|}
\hline Source & df & MS & Fratio & p \\
\hline Day vs. night & 1 & 4.312 & 13.682 & 0.001 \\
Depth & 3 & 1.936 & 6.144 & 0.001 \\
Date & 1 & 18.472 & 58.604 & $<0.001$ \\
Day vs. night $\times$ Depth & 3 & 0.977 & 3.099 & 0.034 \\
Day vs. night $\times$ Date & 1 & 1.491 & 4.730 & 0.034 \\
Depth $\times$ Date & 3 & 0.180 & 0.570 & 0.637 \\
Day vs. night $\times$ Date $\times$ Depth & 3 & 0.029 & 0.092 & 0.964 \\
Error & 55 & 0.315 & & \\
\hline
\end{tabular}

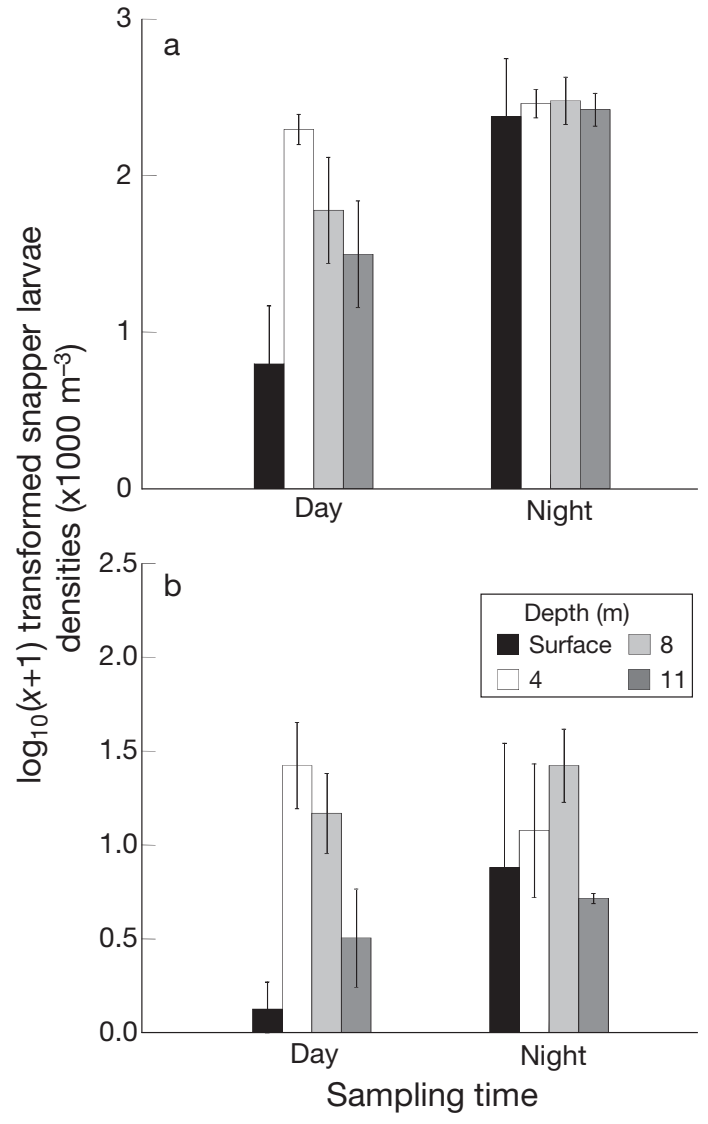

Fig. 2. Chrysophrys auratus. $\log _{10}(x+1)$ transformed densities of snapper larvae in day and night sampling, pooled by depth, in (a) 2008/09 and (b) 2009/10. Mean values \pm SE are shown. Note that the scales are different in (a) and (b)

higher densities at the 4 and $8 \mathrm{~m}$ depths during the day (Fig. 2a,b). There were significant differences in snapper larval densities between the surface and $4 \mathrm{~m}$ (post hoc Tukey: $\mathrm{p}$ < 0.001), 4 and $11 \mathrm{~m}$ (post hoc Tukey: $\mathrm{p}=$ 0.01 ), and surface and $8 \mathrm{~m}$ (post hoc Tukey: $\mathrm{p}<0.001$ ) depth strata. Densities of snapper larvae were not significantly higher at any depth strata during the night in 2008/09 but were generally highest between the surface and $8 \mathrm{~m}$ depths in 2009/10, although there were no significant depth effects (Fig. 2a,b).

\section{Environmental variables}

For the two $24 \mathrm{~h}$ sampling events where enough snapper larvae were sampled to analyse their DVM, there was partial cloud cover and light winds (5 to 10 knots onshore SSW). There was no evidence of a thermocline, as temperature varied less than $1^{\circ} \mathrm{C}$ from surface to bottom. There was no significant difference in temperature between depths in 2008/09 (ANOVA: 

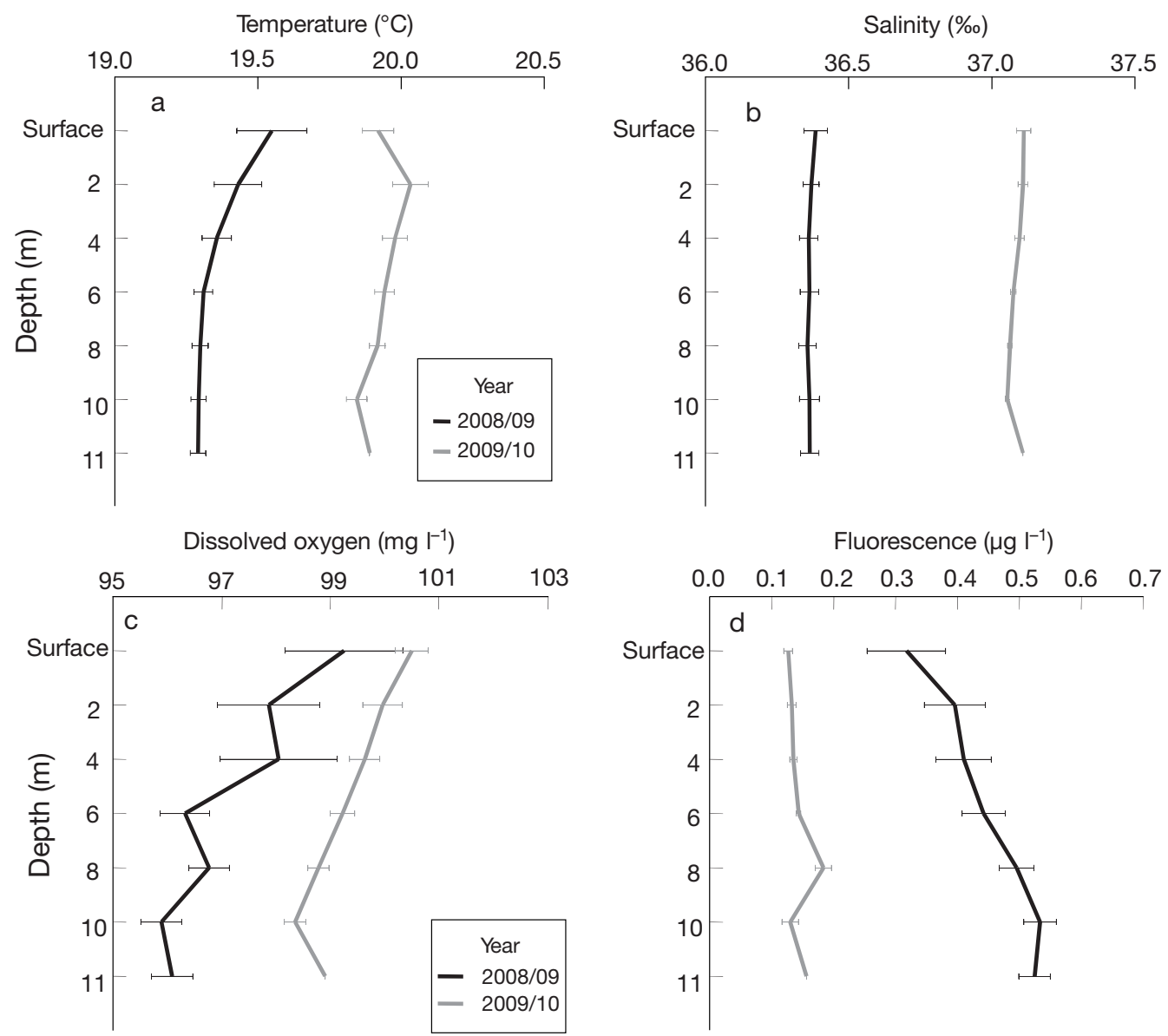

Fig. 3. Depth profiles of measured environmental variables measured every $2 \mathrm{~m}$ (except final sample at $11 \mathrm{~m}$ ) and averaged over a $24 \mathrm{~h}$ period from $2 \mathrm{yr}\left(2008 / 09\right.$ and 2009/10) of sampling: (a) temperature $\left({ }^{\circ} \mathrm{C}\right) ;$ (b) salinity $(\%)$; (c) dissolved oxygen (mg $\left.\mathrm{l}^{-1}\right)$; and (d) fluorescence $\left(\mu \mathrm{g} \mathrm{l}^{-1}\right)$. Mean values $\pm \mathrm{SE}$ are shown

$\mathrm{p}=0.067$ ) (Fig. 3a). Temperature varied significantly between depths in 2009/10 (ANOVA: p = 0.003), and the difference was between the surface and 4,6,8 and $10 \mathrm{~m}$ depths (post hoc Tukey tests: $\mathrm{p}<0.05$ ), not between depths (Fig. 3a). There was also no evidence of a halocline, as salinity did not vary significantly between depths in 2008/09 (ANOVA: $p=0.999$ ) and 2009/10 (ANOVA: $p=0.060$; Fig. 3b). Dissolved oxygen was significantly different by depth in $2008 / 09$ (ANOVA: $\mathrm{p}<0.001$ ) and 2009/10 (ANOVA: $\mathrm{p}<0.001$ ). These differences were between the surface and 6,8 , 10 and $11 \mathrm{~m}$ depths (post hoc Tukey tests: $\mathrm{p}<0.05$ ) in 2008/09, and between the surface and 6, 8 and $10 \mathrm{~m}$ depths (post hoc Tukey tests: $\mathrm{p}<0.05$ ) and between 2 and $8 \mathrm{~m}$ (post hoc Tukey test: p < 0.05) in 2009/10 (Fig. 3c). Fluorescence varied between depths in 2008/ 09 (ANOVA: $p=0.002$ ) and 2009/10 (ANOVA: $p<$ 0.001 ), and these differences were between the surface and 8,10 and $11 \mathrm{~m}$ depths (post hoc Tukey test: $\mathrm{p}<$ 0.05 ) in 2008/09 and between $10 \mathrm{~m}$ and the surface, 2 , 4, 6 and $8 \mathrm{~m}$ depths in 2009/10 (Fig. 3d).

\section{Foraging success of snapper larvae}

Snapper larvae had food in their stomachs from 05:00 to 21:00 $\mathrm{h}$ in 2008/09 and from 05:00 to 19:00 $\mathrm{h}$ in 2009/10 (Fig. 4a,b), and all stomachs were empty by midnight. This allowed us to estimate the digestion time of prey to be between 3 and $5 \mathrm{~h}$, based on the block of sampling where larvae last had prey in their stomachs (at the end of the day at 21:00 $\mathrm{h}$ [2008/09] and 19:00 h [2009/10]) compared to all sampled larvae having empty stomachs in the block of sampling around midnight. For the majority of larvae, the stomach contents were not highly digested, enabling accurate identification and measurement of prey items. There were no clear feeding peaks, with larvae feeding continuously throughout the daylight period (Fig. 4a,b). The samples from 2009/10 had a higher percentage of larvae with food in their stomachs than samples from 2008/09 (Fig. 4a,b).

Analysis of variance of average foraging success of snapper larvae in relation to date, depth and day vs. 


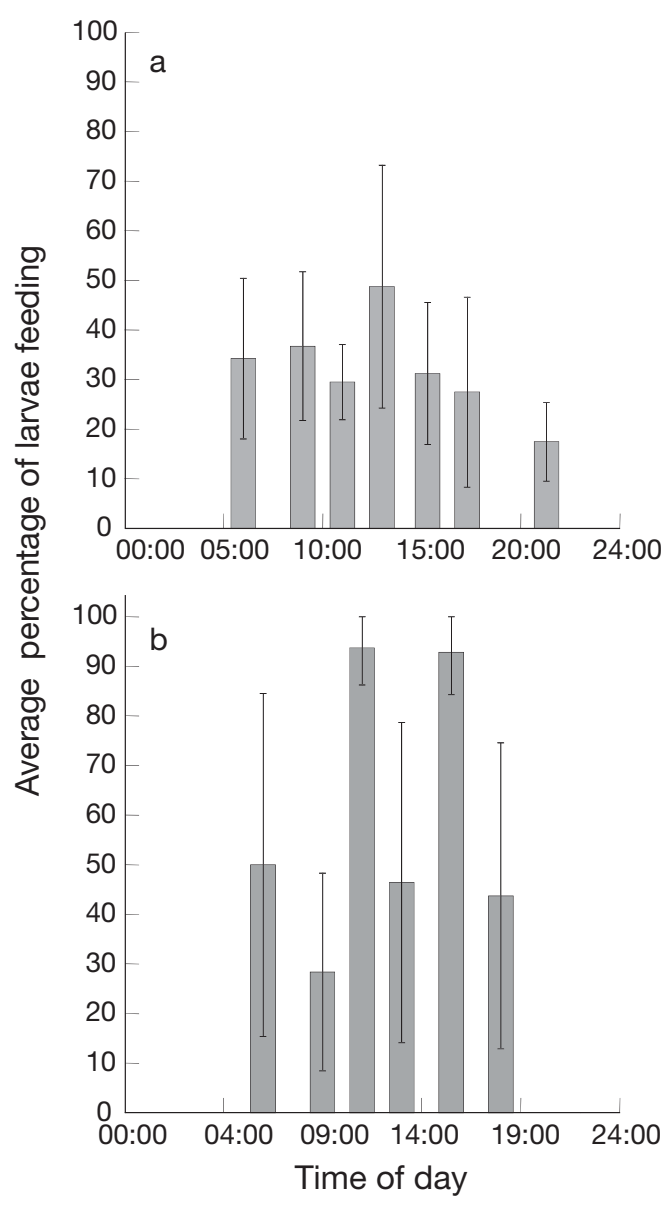

Fig. 4. Chrysophrys auratus. Average percentage of larvae feeding throughout a $24 \mathrm{~h}$ period in (a) 2008/09 and (b) 2009/10. Mean values $\pm \mathrm{SE}$ are shown. Sunrise was at 0:600 $\mathrm{h}$ and sunset at 21:00 h. Larvae had empty stomachs from midnight to sunrise

night sampling indicated a significant interaction between depth strata and day vs. night sampling (Table 2). Snapper larvae only foraged during the day (Fig. $4 \mathrm{a}, \mathrm{b}$ ), and had higher foraging success at $4 \mathrm{~m}$ compared to the other 3 depths in both years (Fig. 5a,b). At $4 \mathrm{~m}$, the larvae had $90 \%$ more food in their stomachs compared to the surface (post hoc Tukey: $\mathrm{p}<0.001$ ), $50 \%$ more compared to $8 \mathrm{~m}$ (post hoc Tukey: $\mathrm{p}<0.001$ ) and $95 \%$ more than at $11 \mathrm{~m}$ (post hoc Tukey: $p<0.001$; Fig. 5a,b).

The diets of snapper larvae differed between years. In 2008/09, snapper larvae had a broad diet that included copepod nauplii, calanoid copepodites, the cladocerans Penilia, Evadne and Podon, invertebrate eggs and bivalve veligers (Fig. 6a). In 2008/09, larvae sampled at the $4 \mathrm{~m}$ depth stratum, where average foraging success was highest, had a diet composed primarily of calanoid copepodites $(40 \%)$ and copepod nauplii (33\%; Fig. 6a). In 2009/10, snapper larvae had a narrower diet breadth, with only 3 prey items domi-

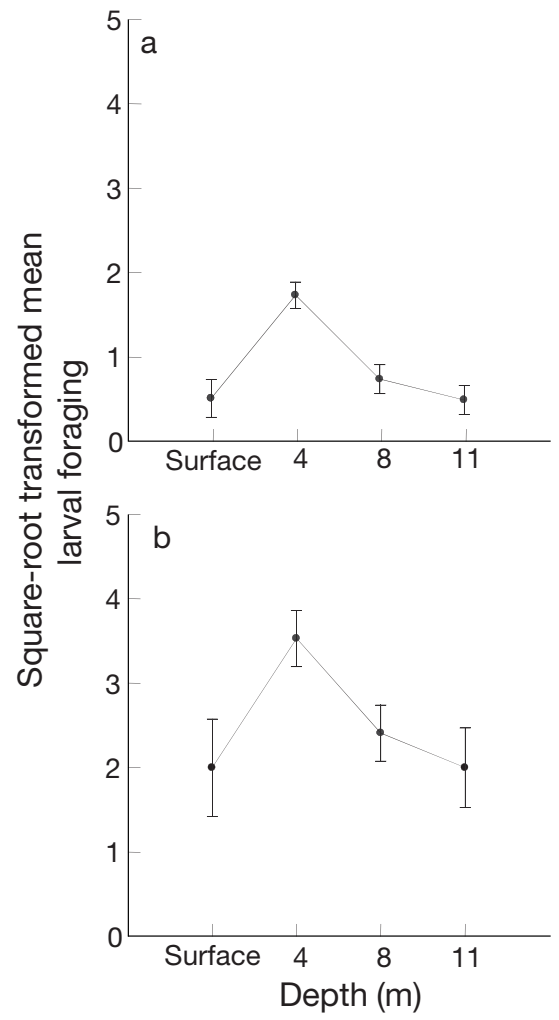

Fig. 5. Chrysophrys auratus. Square-root transformed average foraging success (measured as average number of prey per snapper larva by tow) in daytime tows only, pooled by depth in

(a) 2008/09 and (b) 2009/10. Mean values $\pm \mathrm{SE}$ are shown

Table 2. Chrysophrys auratus. Analysis of variance of squareroot transformed mean larval foraging success with respect to date, depth and day vs. night sampling over 2 sampling periods

\begin{tabular}{|lrrrr|}
\hline Source & df & MS & Fratio & \multicolumn{1}{c|}{$\mathrm{p}$} \\
\hline Day vs. night & 1 & 1.746 & 8.969 & $<0.001$ \\
Depth & 3 & 2.655 & 16.281 & $<0.001$ \\
Date & 1 & 0.027 & 0.168 & 0.683 \\
Day vs. night $\times$ Depth & 3 & 2.096 & 12.853 & $<0.001$ \\
Day vs. night $\times$ Date & 1 & 0.246 & 1.507 & 0.255 \\
Depth $\times$ Date & 3 & 0.374 & 2.293 & 0.088 \\
Day vs. night $\times$ Date $\times$ Depth & 3 & 0.231 & 1.414 & 0.248 \\
Error & 55 & 0.163 & & \\
\hline
\end{tabular}

nating their diet: invertebrate eggs, copepod nauplii and calanoid copepodites (Fig. 6b). At the $4 \mathrm{~m}$ depth stratum, their diet was composed of $75 \%$ copepod nauplii and $21 \%$ calanoid copepodites (Fig. 6b).

\section{Zooplankton}

Only zooplankton taxa/stages that were preyed upon by snapper larvae were considered in the zoo- 

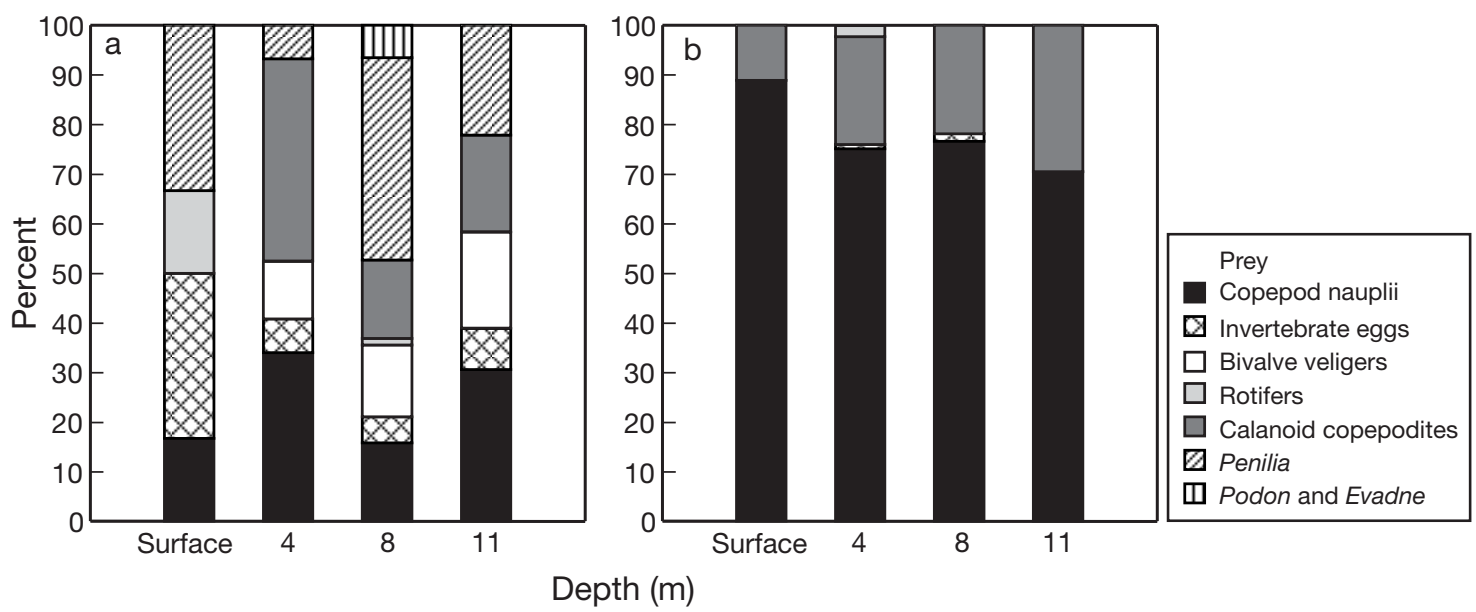

Fig. 6. Chrysophrys auratus. Percent composition of the prey items in the diet of snapper larvae during the day pooled by depth in (a) 2008/09 and (b) 2009/10
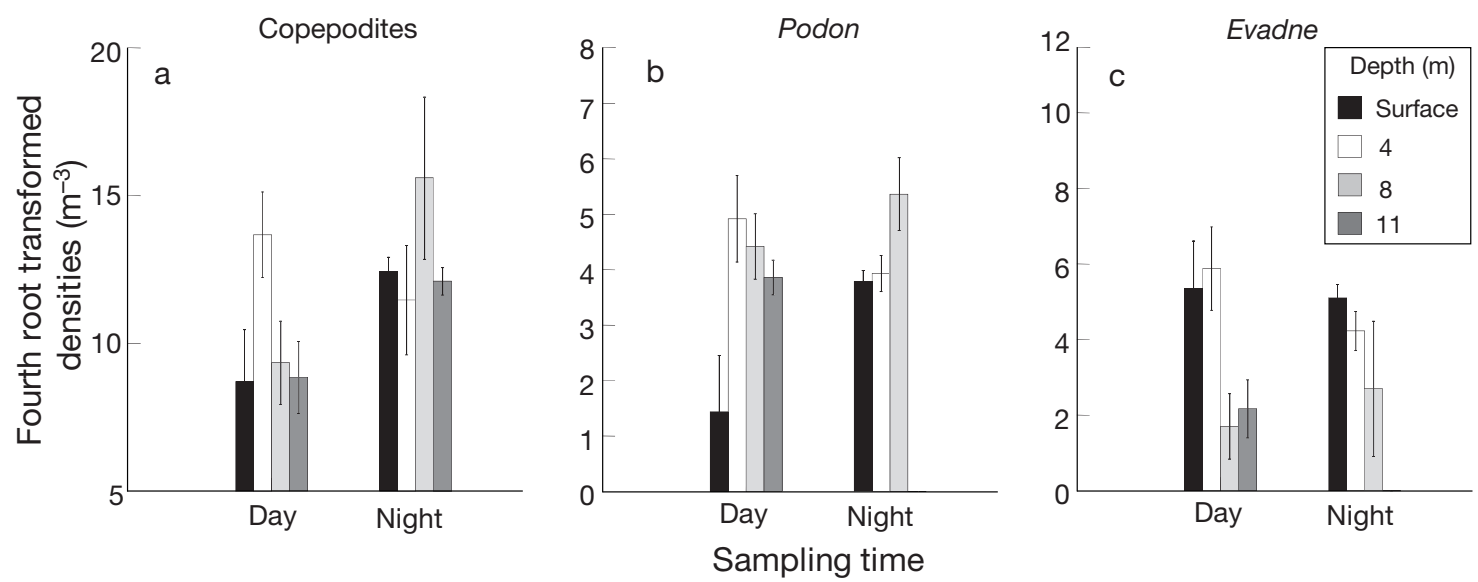

Fig. 7. Fourth-root transformed densities of (a) calanoid copepodites pooled by depth and year (b) Podon pooled by depth and year and (c) Evadne pooled by depth, in 2009/10. Note scales are different in each graph. Mean values \pm SE are shown

plankton analyses. These included copepod nauplii, bivalve veligers, calanoid copepodites and 3 cladoceran genera (Penilia, Podon and Evadne). We were interested in the interaction between day vs. night sampling and depth for zooplankton taxa/stages and how this may relate to DVM behaviour of snapper larvae. Three-factor univariate ANOVA tests indicated depth by day vs. night interactions for both copepodites $\left(F_{3,55}=3.453, \mathrm{p}=0.023\right)$ and Podon $\left(F_{3,55}=\right.$ $3.453, \mathrm{p}=0.001)$. For copepodites, the interaction was driven by depth stratification of copepodites at $4 \mathrm{~m}$ during the day, with increased densities at $4 \mathrm{~m}$ compared to $11 \mathrm{~m}$ (post hoc Tukey: $\mathrm{p}=0.027$ ) and $8 \mathrm{~m}$ (post hoc Tukey: $p=0.038$; Fig. 7a). For Podon, the interaction was driven by lower densities of Podon at $11 \mathrm{~m}$ compared to the surface (post hoc Tukey: $p=0.014$ ), $4 \mathrm{~m}$ (post hoc Tukey: $\mathrm{p}=0.003$ ) and $8 \mathrm{~m}$ (post hoc Tukey: $p=0.005$ ) during the night, and higher densities at $8 \mathrm{~m}$ compared to the surface during the day (post hoc Tukey: p =0.006; Fig. 7b). Evande demonstrated a date by depth interaction $\left(F_{3,55}=4.938, \mathrm{p}=\right.$ 0.004) with higher densities of Evadne at $4 \mathrm{~m}$ compared to $11 \mathrm{~m}$ (post hoc Tukey: $\mathrm{p}=0.001$ ) and $8 \mathrm{~m}$ (post hoc Tukey: $p=0.002$ ), and increased densities at the surface compared to $11 \mathrm{~m}$ (post hoc Tukey: $\mathrm{p}=0.005$ ) and $8 \mathrm{~m}$ (post hoc Tukey: $\mathrm{p}=0.008$ ) in 2009/10 (Fig. $7 \mathrm{c}$ ). Correlations of transformed snapper larval densities and zooplankton taxa/stages was significant for Penilia densities $(\mathrm{R}=0.674, \mathrm{p}<0.001)$ employing a conservative $\mathrm{p}$ value of 0.004 to account for multiple testing (i.e. 2 dates $\times 6$ zooplankton taxa/stages).

\section{DISCUSSION}

Snapper larvae in PPB exhibited nocturnal diffusion and aggregation at a specific depth stratum during the day. For 2 sampling times in different years, larvae ag- 
gregated during the day around $4 \mathrm{~m}$ at our sampling site, which had a maximum depth of $12 \mathrm{~m}$. Aggregation during the day and nocturnal diffusion have been seen in other marine fish larvae, including sandeel (Jensen et al. 2003), King George whiting Sillaginodes punctata (Jenkins et al. 1998) and herring Clupea harengus (Haslob et al. 2009). However, nocturnal ascent, rather than nocturnal diffusion, is more commonly seen in other larval sparid species, including the closely related Pagrus major (e.g. Tanaka 1985, Kinoshita \& Tanaka 1990). Diel vertical migratory behaviour demonstrated by estuarine sparid species is thought to influence dispersal into, or retention in, estuarine nursery habitat (e.g. Kinoshita \& Tanaka 1990, Forward et al. 1998, Trnski 2001). In our study on a sparid that is not estuarine dependent, and spawns immediately in the known settlement and nursery areas (Hamer et al. 2010, 2011), DVM behaviour of larvae would appear unlikely to be related to dispersal or retention advantages, but more likely to be related to other benefits to larval survival, such as foraging success.

Consistent aggregation at the $4 \mathrm{~m}$ depth stratum by snapper larvae was accompanied by higher foraging success, albeit on different prey items on each sampling date. While it is possible that the snapper larvae caught at $4 \mathrm{~m}$ did not feed at this depth, prey were not highly digested in the majority of samples, suggesting recent ingestion (Young \& Davis 1992). While the estimate of 3 to $5 \mathrm{~h}$ for gut evacuation for snapper larvae in the field has not been tested in the laboratory, this evacuation rate is similar to other temperate larval

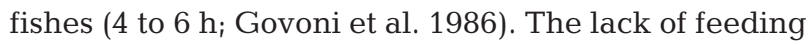
by snapper larvae at night coupled with their diffusion throughout the water column supports a link between feeding behaviour and the observed DVM. Diffusion of the larvae at night could also be in response to relaxation or removal of a gradient, such as light, and the larvae were then passively responding to turbulence (Munk et al. 1989, Ponton \& Fortier 1992) or were not able to regulate their depth in the absence of light (Leis 2004).

The consistent DVM behaviour of snapper larvae in our study occurred despite vertical homogeneity for the majority of environmental parameters (temperature, salinity, dissolved oxygen and fluorescence) in both the day and night sampling. The lack of water column stratification observed in our sampling periods is consistent with other studies in PPB (Black et al. 1993). Two of the 6 zooplankton taxa/stages were aggregated at $4 \mathrm{~m}$ during the day (copepodites and Evadne in 2009/10), which may have influenced the vertical behaviour of snapper larvae. However, the majority of the zooplankton prey were not stratified in the water column, except for Podon, which had type I DVM (up at dusk and down at dawn). There was a strong corre- lation between snapper larval densities and Penilia densities, although Penilia were not stratified in the water column. This strong correlation may be a reflection of similar processes influencing the patchiness of both snapper larvae and Penilia densities, and the higher densities of both at night. Our measured environmental variables do not clearly explain the DVM behaviour and high foraging success of snapper larvae at $4 \mathrm{~m}$. However, other unmeasured variables, such as light, turbulence and predators, may have had an effect on larval DVM behaviour.

The influence of optimal light levels for foraging success on the vertical behaviour of marine fish larvae has been found in Arctic cod Boreogadus saida (Ponton \& Fortier 1992), sand lance Ammodytes sp. (Gilbert et al. 1992, Ponton \& Fortier 1992) and herring (Munk et al. 1989). Furthermore, in previous studies where zooplankton prey and environmental variables were not stratified, fish larvae were found to aggregate near the surface to obtain optimal feeding conditions (Fortier \& Leggett 1983, Munk et al. 1989, Jensen et al. 2003). Snapper larvae are visual feeders (Pankhurst et al. 1991), and previous work in aquaculture studies has found that photoperiod alone has a profound effect on development of snapper larvae, with long photoperiods (up to $18 \mathrm{~h} \mathrm{~d}^{-1}$ ) thought to improve the performance of snapper larvae by providing more feeding opportunities (Fielder et al. 2002). While light attenuation was not measured during these 2 sampling periods, data on light attenuation at this sampling site in December 2010 showed high light attenuation (light attenuation coefficient $0.33 \mathrm{~m}^{-1} ; \mathrm{H}$. Murphy unpubl. data). Chl a concentrations were higher in 2010/11 than the previous 2 years ( $\mathrm{H}$. Murphy unpublished data), so light attenuation may have been lower during our $24 \mathrm{~h}$ sampling, with more light reaching the 4 and $8 \mathrm{~m}$ strata in 2008/09 and 2009/10 compared to 2010/ 11. Snapper larvae may have been avoiding the surface due to UV radiation (Browman 2003), and positioned themselves at a depth where there was a tradeoff between light and prey availability, which resulted in high foraging success and aggregation at $4 \mathrm{~m}$.

Turbulence may affect the feeding success and vertical behaviour of snapper larvae. The influence of increased microscale turbulence on larval feeding can be positive with increased gut fullness as the size of the prey consumed by larvae increases (Dower et al. 1998), but increased turbulence can also reduce the probability of larvae catching their pursued prey (MacKenzie \& Kiorboe 2000, Werner et al. 2001). Obtaining optimal turbulence levels for predator-prey encounters and capture may play an important role in larval vertical behaviour. This question can be addressed by using hydrodynamic modelling of turbulence velocities at different depths within a survey site. 
Avoidance of predators may also affect the vertical behaviour of fish larvae (Neilson \& Perry 1990). The presence of piscivorous and gelatinous zooplankton predators in the vicinity of fish larval patches could be expected to have an effect on the vertical distribution of fish larvae (e.g. Brewer et al. 1984, Yamashita et al. 1985). While we did not directly measure the presence of gelatinous and piscivorous predators while sampling, future research using echosounders to measure the presence of schooling predators and using surveys to count and identify gelatinous predators would provide information on number and type of predators that larvae are encountering.

DVM behaviour may become more pronounced as marine fish larvae develop ontogenetically (reviewed by Neilson \& Perry 1990). We found that snapper larvae aggregated around $4 \mathrm{~m}$ during the day irrespective of size class, from newly hatched to flexion. The majority of larvae we sampled were $16 \mathrm{~d}$ post hatch or younger, and it is thought that snapper larvae settle after 3 to $4 \mathrm{wk}$ (at approximately 10 to $12 \mathrm{~mm} \mathrm{SL}$; Battaglene \& Talbot 1992). We were not able to sample pre-settlement, late-stage snapper larvae, which could be a result of net avoidance via detection of water movement from the net. Alternatively, late-stage snapper larvae may be closely associated with the bottom and therefore were missed by our nets, which fished at approximately $1 \mathrm{~m}$ off the bottom for the deepest stratum. In a previous study, settlement-stage snapper larvae were found to demonstrate directional swimming behaviour and were closely associated with the soft bottom of an estuary in New South Wales, Australia (Trnski 2002), and have been previously captured in PPB and Victorian estuaries using a small demersal beam trawl (Hamer \& Jenkins 2004). It is possible that DVM behaviour may be lacking in late-stage (postflexion) snapper larvae, or at least markedly different than the younger larvae in our samples.

In conclusion, snapper larvae were found to demonstrate DVM behaviour, specifically nocturnal diffusion and aggregation around the $4 \mathrm{~m}$ depth during the day in 2 rounds of $24 \mathrm{~h}$ sampling. This aggregation around $4 \mathrm{~m}$ during the day appears to be linked to foraging success, although the drivers behind higher foraging success at this depth were unclear, as the majority of the measured environmental variables were not stratified in the water column. While it is unlikely that the pattern of nocturnal diffusion and daytime aggregation will change spatially and temporally, further work is required to determine how bottom depth, different climatic conditions (i.e. cloud cover, wind, air pressure) and predator abundance may affect the consistency of the aggregation depth in this species. This study provides further evidence of DVM behaviour in early to flexion-stage fish larval development, and, while in this instance the DVM behaviour may not be directly related to providing a dispersal or retention advantage, the behaviour could have an important influence on horizontal dispersal of larvae and their interactions with prey and predator fields. Irrespective of the proximal drivers of DVM, it is important to consider the nature of this behaviour when attempting to explain and model the processes that influence larval survival and subsequent juvenile recruitment (Leis 2006, 2007).

Acknowledgements. We thank S. Acevedo, A. Brown, J. Kent, J. Hommelhoff and T. Smith for help in the field and laboratory, and N. Tolimieri and 3 anonymous reviewers for constructive comments on an earlier draft. This project was funded by an Australian Research Council Linkage Grant (LP0989432) between the Department of Primary Industries, Fisheries Victoria and the University of Melbourne.

\section{LITERATURE CITED}

Battaglene SC, Talbot RB (1992) Induced spawning and larval rearing of snapper, Pagrus auratus (Pisces, Sparidae), from Australian waters. N Z J Mar Freshw Res 26:179-183

Black K, Hatton D, Rosenberg M (1993) Locally and externally-driven dynamics of a large semi-enclosed bay in southern Australia. J Coast Res 9:509-538

Blaxter JHS (1986) Development of sense organs and behaviour of teleost larvae with special reference to feeding and predator avoidance. Trans Am Fish Soc 115:98-114

Brewer GD, Kleppel GS (1986) Diel vertical distribution of fish larvae and their prey in nearshore waters of southern California. Mar Ecol Prog Ser 27:217-226

Brewer GD, Kleppel GS, Dempsey M (1984) Apparent predation on ichthyoplankton by zooplankton and fishes in nearshore waters of southern California. Mar Biol 80: $17-28$

Browman HI (2003) Assessing the impacts of solar ultraviolet radiation on the early life stages of crustacean zooplankton and ichthyoplankton in marine coastal systems. Estuaries 26:30-39

Davis TLO, Jenkins GP, Young JW (1990) Diel patterns of vertical distribution in larvae of southern bluefin Thunnus maccoyii, and other tuna in the East Indian Ocean. Mar Ecol Prog Ser 59:63-74

De LaFontaine Y, Gascon D (1989) Ontogenetic variation in the vertical distribution of eggs and larvae of Atlantic mackerel (Scomber scombrus). Rapp P-V Réun Cons Int Explor Mer 191:137-145

Dower JF, Pepin P, Leggett WC (1998) Enhanced gut fullness and an apparent shift in size selectivity by radiated shanny (Ulvaria subbifurcata) larvae in response to increased turbulence. Can J Fish Aquat Sci 55:128-142

Fielder DS, Bardsley WJ, Allan GL, Pankhurst PM (2002) Effect of photoperiod on growth and survival of snapper Pagrus auratus larvae. Aquaculture 211:135-150

Fortier L, Leggett WC (1983) Vertical migrations and transport of larval fish in a partially mixed estuary. Can J Fish Aquat Sci 40:1543-1555

Forward RB Jr, Tankersley RA, Reinsel KA (1998) Selective tidal stream transport of spot (Leistomus xanthurus Lacepede) and pinfish [Lagodon rhomboides (Linnaeus)] larvae: contribution of circatidal rhythms in activity. J Exp Mar Biol Ecol 226:19-32

Fowler AJ, Jennings PR (2003) Dynamics in 0+ recruitment 
and early life history for snapper (Pagrus auratus, Sparidae) in South Australia. Mar Freshw Res 54:941-956

Fox CJ, McCloghrie P, Young EF, Nash RDM (2006) The importance of individual behaviour for successful settlement of juvenile plaice (Pleuronectes platessa L.): a modelling and field study in the eastern Irish Sea. Fish Oceanogr 15:301-313

Francis MP (1993) Does water temperature determine year class strength in New Zealand snapper (Pagrus auratus, Sparidae)? Fish Oceanogr 2:65-72

Gilbert M, Fortier L, Ponton D, Drolet R (1992) Feeding ecology of marine fish larvae across the Great Whale River plume in seasonally ice-covered southeastern Hudson Bay. Mar Ecol Prog Ser 84:19-30

Govoni JJ, Boehlert GW, Watanabe Y (1986) The physiology of digestion in fish larvae. Environ Biol Fishes 16:59-77

Hamer PA, Jenkins GP (2004) High levels of spatial and temporal recruitment variability in the temperate sparid Pagrus auratus. Mar Freshw Res 55:663-673

Hamer PA, Jenkins GP, Acevedo S (2010) Importance of spawning in Port Phillip Bay to local snapper stocks. Fisheries Victoria Research Report Series No 37, Queenscliff

Hamer PA, Acevedo S, Jenkins GP, Newman A (2011) Connectivity of a large embayment and coastal fishery: spawning aggregations in one bay source local and broadscale fishery replenishment. J Fish Biol 78:1090-1109

> Haslob H, Rohlf N, Schnack D (2009) Small scale distribution patterns and vertical migration of North Sea herring larvae (Clupea harengus, Teleostei: Clupeidea) in relation to abiotic and biotic factors. Sci Mar 73:13-22

> Jenkins GP, Welsford DC, Keough MJ, Hamer PA (1998) Diurnal and tidal vertical migration of presettlement King George whiting Sillaginodes punctata in relation to feeding and vertical distribution of prey in a temperate bay. Mar Ecol Prog Ser 170:239-248

Jensen H, Wright PJ, Munk P (2003) Vertical distribution of pre-settled sandeel (Ammodytes marinus) in the North Sea in relation to size and environmental variables. ICES J Mar Sci 60:1342-1351

Joyeux JC (2001) The retention of fish larvae in estuaries: among-tide variability at Beaufort Inlet, North Carolina, USA. J Mar Biol Assoc UK 81:857-868

Kinoshita I, Tanaka M (1990) Differentiated spatial distribution of larvae and juveniles of the two sparids, red and black sea bream, in Shijiki Bay. Nippon Suisan Gakkaishi 56:1807-1813

Kiorboe T, Munk P, Stottrup JG (1985) First feeding by larval herring Clupea harengus L. Dana 5:95-107

Leis JM (2004) Vertical distribution behaviour and its spatial variation in late-stage larvae of coral-reef fishes during the day. Mar Freshw Behav Physiol 37:65-88

Leis JM (2006) Are larvae of demersal fishes plankton or nekton? Adv Mar Biol 51:57-141

> Leis JM (2007) Behaviour as input for modelling dispersal of fish larvae: behaviour, biogeography, hydrodynamics, ontogeny, physiology and phylogeny meet hydrography. Mar Ecol Prog Ser 347:185-193

MacKenzie BR, Kiorboe T (2000) Larval fish feeding and turbulence: a case for the downside. Limnol Oceanogr 45: $1-10$

McGlennon D, Jones GK, Baker J, Jackson WB, Kinloch MA (2000) Ageing, catch-at-age and relative year-class strength for snapper (Pagrus auratus) in northern Spencer Gulf, South Australia. Mar Freshw Res 51:669-677
Munk P, Kiorboe T, Christensen V (1989) Vertical migrations of herring, Clupea harengus, larvae in relation to light and prey distribution. Environ Biol Fishes 26:87-96

Neilson JD, Perry RI (1990) Diel vertical migrations of marine fishes: an obligate or facultative process? Adv Mar Biol 26: 115-168

Neira FJ, Miskiewicz AG, Trnski T (1998) Larvae of temperate Australian fishes-laboratory guide for larval fish identification. University of Western Australia Press, Nedlands

Pankhurst PM, Montgomery JC, Pankhurst NW (1991) Growth, development and behaviour of artificially reared larval Pagrus auratus (Bloch and Schneider, 1801) (Sparidae). Aust J Mar Freshw Res 42:391-398

Ponton D, Fortier L (1992) Vertical distribution and foraging of marine fish larvae under the ice cover of southeastern Hudson Bay. Mar Ecol Prog Ser 81:215-227

Ruso YP, Bayle-Sempere JT (2006) Diel and vertical movements of preflexion fish larvae assemblages associated with Posidonia oceanica beds. Sci Mar 70:399-406

Sabates A (2004) Diel vertical distribution of fish larvae during the winter-mixing period in the northwestern Mediterranean. ICES J Mar Sci 61:1243-1252

Sclafani M, Taggart CT, Thompson KR (1993) Condition, buoyancy and the distribution of larval fish: implications for vertical migration and retention. J Plankton Res 15: 413-435

Sponaugle S, Cowen RK, Shanks A, Morgan SG and others (2002) Predicting self-recruitment in marine populations: biophysical correlates and mechanisms. Bull Mar Sci 70: 341-375

Tanaka M (1985) Factors affecting the inshore migration of pelagic larval and demersal juvenile red sea bream Pagrus major to a nursery ground. Trans Am Fish Soc 114: 471-477

Theilacker GH (1980) Changes in body measurements of larval northern anchovy, Engraulis mordax, and other fishes due to handling and preservation. Fish Bull 78:685-692

> Trnski T (2001) Diel and tidal abundance of fish larvae in a barrier-estuary channel in New South Wales. Mar Freshw Res 52:995-1006

Trnski T (2002) Behaviour of settlement-stage larvae of fishes with an estuarine juvenile phase: in situ observations in a warm-temperate estuary. Mar Ecol Prog Ser 242:205-214

Vikebø F, Jørgensen C, Kristiansen T, Fiksen Ø (2007) Drift, growth, and survival of larval Northeast Arctic cod with simple rules of behaviour. Mar Ecol Prog Ser 347:207-219

Werner FE, MacKenzie BR, Perry RI, Lough RG, Naimie CE, Blanton BO, Quinlan JA (2001) Larval trophodynamics, turbulence, and drift on Georges Bank: a sensitivity analysis of cod and haddock. Sci Mar 65:99-115

Yamashita Y, Kitagawa D, Aoyama T (1985) Diel vertical migration and feeding rhythm of the larvae of the Japanese sand eel Ammodytes personatus. Bull Jpn Soc Sci Fish 51:1-5

> Young JW, Davis TLO (1992) Feeding ecology and interannual variations in diet of larval jack mackerel, Trachurus declivis (Pisces, Carangidae), from coastal waters of eastern Tasmania. Mar Biol 113:11-20

Zeldis JR, Oldman J, Ballara SL, Richards LA (2005) Physical fluxes, pelagic ecosystem structure, and larval fish survival in Hauraki Gulf, New Zealand. Can J Fish Aquat Sci 62:593-610

Submitted: November 16, 2010; Accepted: April 20, 2011 Proofs received from author(s): June 29, 2011 